\title{
A GREENHOUSE GAS EMISSIONS INVENTORY FOR SOUTH AFRICA: A COMPARATIVE ANALYSIS
}

\author{
R. Seymore ${ }^{1}$, R. Inglesi-Lotz ${ }^{1}$ and J. Blignaut ${ }^{1}$
}

\begin{abstract}
An energy-based greenhouse gas (GHG) emissions inventory for South Africa for various years is presented, but most notably an estimate for 2008, in terms of industrial sectors using the energy balances of South Africa is given. This figure is estimated to be between 470000 and $550000 \mathrm{Gg}$ of $\mathrm{CO}_{2}$-equiv. with the higher number probably being a more realistic reflection. This information is compared to six other inventories to i) assess the robustness of the results presented, and ii) to comment on the stability of the inventories available.

From this comparative analysis it is evident that major discrepancies exist among the inventories both in terms of scope (i.e. sectors and gas composites included) as well as method of estimation used. These differences hamper the efficacy of, among others, any economic modelling exercise related to carbon emissions, such as estimating the impact of carbon taxes on the country. It is therefore argued that a consistent, robust and replicable framework for estimating GHG emissions that would also render timeous results, should be adopted.
\end{abstract}

JEL Classification Numbers: C82, Q56

Keywords: Energy Balances, Carbon Emissions Inventory, Emissions Factors, IPCC, South Africa

\section{INTRODUCTION}

South Africa, as the leading economy in the Sub-Saharan Africa, is also the negative leader in greenhouse gas emissions (GHG) in the continent. The high emissions profile of the country is linked with the economy's production and growth. Policy makers have made international commitments but also they have shown initiatives locally to reduce the country's GHG emissions. They appreciate highly the country's, as well as the continent's, vulnerability to climate change due to the geographical position and the more traditional nature of the African developing economies. However, a desire to improve is not adequate without knowledge of the current emitting profile of the country and its evolution through the years until now.

Here a comparative analysis among the various GHG emission inventories of South Africa is conducted, and in the process new inventories for 2007 and 2008 are constructed. In an effort to start with an holistic picture of the status quo of the country's inventories, we first analyse and review the South African Department of Energy (DoE), the South African Department of Environmental Affairs and Tourism (DEAT), the International Energy Agency (IEA), Scholes and van der Merwe (1996), Howells and Solomon (2000), and Blignaut et al. (2005). Not only are these emission inventories relatively dated and requiring an update, but they also make use of different methodologies and report on the emissions using different industrial classifications. All these locally and internationally sourced databases will be used as a reference and comparative points to our results. They will also serve as part of

${ }^{1}$ Department of Economics. University of Pretoria. 
the motivation for the need or not of an all-inclusive, robust and easily updated new database.

This paper proposes a consistent and theoretical rigorous approach to construct a reliable and timeous GHG emissions inventory. To accomplish this task, this paper develops GHG emissions databases for 2007 and 2008 in terms of industrial sectors, using the energy balances of South Africa.

In the next section a brief overview of existing GHG inventories for South Africa is provided. The third section provides the inventory construction method used in this study. Thereafter, the results are discussed, followed by an analysis on the robustness of the results. Lastly, a conclusion with recommendations is provided.

\section{BACKGROUND}

\subsection{Introduction}

South Africa is the $13^{\text {th }}$ highest $\mathrm{CO}_{2}$ equiv.-emitter among nations (according to annual emissions in 2008). This constitutes $1.4 \%$ of combined global anthropogenic GHG emissions [1]. In 2008, however, South Africa was ranked $28^{\text {th }}$ in the world with respect to GDP and its global share in GDP was only $0.45 \%$ [2]. Therefore, there is a stark contrast between what the country contributes to GDP and what it contributes to GHG emissions. This anomaly is clearly reflected in the fact that the country's disproportionate contribution of global $\mathrm{CO}_{2}$ is 3.1 times that of its contribution to global GDP. A careful analysis of South Africa's GHG emissions profile and subsequent action to reduce (mitigate) its emissions is needed. It also requires the construction of robust and timeous GHG emission inventories that underpins much of the mitigation analysis and action. To date there are six sources of GHG emission inventories, namely:

- The inventory published by Scholes and Van der Merwe [3] for 1988,

- The inventory published by Howells and Solomon [4] for 1994,

- The Department of Environmental Affairs and Tourism inventories for 1990, 1994 and 2000,

- The Department of Energy inventories for 2007 and 2008,

- The International Energy Agency's inventories for 1971, 1975, 1980, 1985, 1990, 1995, 2000, 2005, 2007, 2008 and 2009, and

- The inventory published by Blignaut et al. [5] for 1998.

These inventories are briefly discussed below and summarised in Table 1. 
Table 1: South African GHG emission inventories

\begin{tabular}{|c|c|c|c|c|c|}
\hline & Years & $\begin{array}{l}\text { IPCC } \\
\text { guidelines }\end{array}$ & GHGs included & Disaggregation & Limitations \\
\hline $\begin{array}{l}\text { Scholes } \\
\text { and Van } \\
\text { der } \\
\text { Merwe [3] }\end{array}$ & 1988 & 1996 & $\begin{array}{l}\mathrm{CO}_{2}, \mathrm{CH}_{4}, \mathrm{~N}_{2} \mathrm{O}, \mathrm{NO}_{\mathrm{x}} \\
\mathrm{CO} \text { AND NMVOC }\end{array}$ & $\begin{array}{l}\text { By activity and } \\
\text { technology }\end{array}$ & $\begin{array}{l}\text { Relatively dated } \\
\text { Activities not consistent } \\
\text { with current structure of } \\
\text { national energy balances }\end{array}$ \\
\hline $\begin{array}{l}\text { Howells } \\
\text { and } \\
\text { Solomon } \\
{[4]}\end{array}$ & 1994 & 1996 & $\begin{array}{l}\mathrm{CO}_{2}, \mathrm{CH}_{4}, \mathrm{~N}_{2} \mathrm{O}, \mathrm{NO}_{\mathrm{X}} \\
\mathrm{CO}, \mathrm{NMVOC} \text { and } \mathrm{SO}_{2}\end{array}$ & $\begin{array}{l}\text { By activity and } \\
\text { fuel type }\end{array}$ & $\begin{array}{l}\text { Relatively dated } \\
\text { Activities not consistent } \\
\text { with current structure of } \\
\text { national energy balances } \\
\end{array}$ \\
\hline DEAT [6] & $\begin{array}{l}1990 \\
1994 \\
2000\end{array}$ & $\begin{array}{l}1996 \\
1996 \\
2000\end{array}$ & $\begin{array}{l}1990 \text { and 1994: } \\
\mathrm{CO}_{2}, \mathrm{CH}_{4} \text { and } \mathrm{N}_{2} \mathrm{O} \\
2000: \\
\mathrm{CO}_{2}, \mathrm{CH}_{4}, \mathrm{~N}_{2} \mathrm{O}, \mathrm{HFC} \text { 's, } \\
\text { PFCs and } \mathrm{SF}_{6} \text {, }\end{array}$ & By sector & Different IPCC guidelines \\
\hline DOE $[7,8]$ & $\begin{array}{l}2007 \\
2008\end{array}$ & $\begin{array}{l}1996 \\
1996\end{array}$ & $\begin{array}{l}\mathrm{CO}_{2} \text { and } \mathrm{CO}_{2} \\
\text { equivalent }\end{array}$ & $\begin{array}{l}\text { By sector and } \\
\text { industry }\end{array}$ & $\begin{array}{l}\text { Assumes that nuclear } \\
\text { and renewable energy } \\
\text { carriers do not emit at all } \\
\text { (transformation sector). } \\
\text { Assumes that sectors } \\
\text { such as 'non-ferrous } \\
\text { metals', 'transport } \\
\text { equipment', 'textile and } \\
\text { leather', 'international } \\
\text { civil aviation', 'domestic } \\
\text { air transport' and } \\
\text { 'pipeline transport' do not } \\
\text { emit. }\end{array}$ \\
\hline IEA [9] & $\begin{array}{l}1971 \\
1975 \\
1980 \\
1985 \\
1990 \\
1995 \\
\end{array}$ & $\begin{array}{l}1996 \\
1996 \\
1996 \\
1996 \\
1996 \\
1996 \\
\end{array}$ & $\mathrm{CO}_{2}$ & $\begin{array}{l}\text { By sector and } \\
\text { fuel type }\end{array}$ & Only $\mathrm{CO}_{2}$ \\
\hline $\begin{array}{l}\text { Blignaut } \\
\text { et al [5] }\end{array}$ & 1998 & 1996 & $\mathrm{CO}_{2}, \mathrm{CH}_{4}$ and $\mathrm{N}_{2} \mathrm{O}$ & $\begin{array}{l}\text { By sector and } \\
\text { fuel type }\end{array}$ & $\begin{array}{l}\text { Relatively dated } \\
\text { Only } 1996 \text { IPCC } \\
\text { guidelines }\end{array}$ \\
\hline
\end{tabular}

2.2 The inventory based on Scholes and Van der Merwe (1996)

Scholes and Van der Merwe [3] published the first comprehensive inventory of gas emissions from South Africa, for the year 1988. The inventory includes $\mathrm{CO}_{2}, \mathrm{CH}_{4}$, $\mathrm{N}_{2} \mathrm{O}, \mathrm{NO}_{x}, \mathrm{CO}$ and NMVOC gas emissions by activity ${ }^{2} . \mathrm{CO}_{2}$ emissions were calculated by a "top-down" approach, based on national energy balances. In other words, the energy values of the primary energy sources are converted to the amount of carbon that each source represents. $\mathrm{CH}_{4}, \mathrm{~N}_{2} \mathrm{O}, \mathrm{NO} \mathrm{X}_{\mathrm{x}} \mathrm{CO}$ and NMVOC

\footnotetext{
2 The activity categories used: Electricity generation, Industrial stationary combustion, Residential/domestic stationary combustion, Wood and bagasse-fired industrial process, Road, air, rail and sea transport, Coal mining, Cement and lime manufacturing, Land filling, Enteric fermentation, Decay of wild animal wastes, Nitrogenous fertilisers, Termites, Cultivation of virgin grasslands, Plantations, Non-sustainable fuel wood use, Burning of natural vegetation and Burning of agricultural crop wastes.
} 
were calculated by a "bottom-up" approach, based on the type of activity and technology used. Emission factors for each gas were used to calculate the emissions of each gas from the various sources. The emissions factors of the Intergovernmental Panel on Climate Change (IPCC) were used where South African values were not available. Where a range of IPCC emissions factors existed, the average between the minimum and maximum values were used. An index of South Africa's contribution to global warming was calculated by converting $\mathrm{CH}_{4}$ and $\mathrm{N}_{2} \mathrm{O}$ to $\mathrm{CO}_{2}$ equivalents by using their 20-year integrated global warming potentials.

The total emissions as calculated provides a useful reference point for 1988, but cannot be used for a comparative analysis on a more disaggregated level since the activity classification is not consistent with the current structure of national energy balances.

\subsection{The inventory based on Howells and Solomon [4]}

Howells and Solomon [4] published a GHG energy emissions inventory for the year 1994. A top-down $\mathrm{CO}_{2}$ inventory was compiled according to the IPCC's reference approach and based on the official disaggregated national energy balance obtained from the Department of Minerals and Energy (DME). $\mathrm{CO}_{2}$ emissions were estimated based on the amount of fossil fuels consumed in the country in a given year, the fuels' calorific values and their total carbon contents. The top-down approach reports $\mathrm{CO}_{2}$ emissions by fuel type ${ }^{3}$.

A bottom-up GHG inventory was compiled for $\mathrm{CO}_{2}, \mathrm{CH}_{4}, \mathrm{~N}_{2} \mathrm{O}, \mathrm{NO} \mathrm{x}_{\mathrm{x}} \mathrm{CO}$, NMVOC and $\mathrm{SO}_{2}$ emissions per activity. Sectoral fuel consumptions were estimated and emissions factors were used to calculate carbon emissions. The total carbon emissions for each sector were calculated by summing carbon emissions from each fuel type used in each sector. These results were presented as percentage of $\mathrm{CO}_{2}$, $\mathrm{CH}_{4}, \mathrm{~N}_{2} \mathrm{O}, \mathrm{NO}_{x}, \mathrm{CO}, \mathrm{NMVOC}$ and $\mathrm{SO}_{2}$ emissions per activity.

\subsection{The Department of Environmental Affairs and Tourism's inventories}

The South African Department of Environment Affairs and Tourism (DEAT) published the Greenhouse Gas Inventory South Africa 1990 to 2000 in 2009 [6] under the United Nations Framework Convention on Climate Change (UNFCCC). Inventories have been constructed for 1990, 1994 and 2000. The 1990 and 1994 inventories were based on 1996 IPCC guidelines and the data were obtained from the national energy balance. The 2000 inventory was based on the 2006 IPCC guidelines and data were also obtained from the relevant national energy balance. The 2000 inventory includes $\mathrm{CO}_{2}$ as well as $\mathrm{CO}_{2}$ equivalent for $\mathrm{CH}_{4}, \mathrm{~N}_{2} \mathrm{O}, \mathrm{HFC}$ 's, PFCs and $\mathrm{SF}_{6}$, while the 1990 and 1994 inventories include $\mathrm{CO}_{2}$ as well as $\mathrm{CO}_{2}$ equivalent for $\mathrm{CH}_{4}$ and $\mathrm{N}_{2} \mathrm{O}$. All three inventories report emissions by sector. However, in the 2000 inventory agriculture, forestry and land use has been aggregated into one sector, as per 2006 IPCC guidelines. Boyd et al [10] in a report prepared for the World Resources Institute (WRI), provides, as part of a case

3 Fuel types reported: Crude oil, Orimulsion, Natural gas liquids, Gasoline, Jet Kerosene, Shale oil, Gas/Diesel oil, Residual fuel oil, LPG, Ethane, Naphtha, Bitumen, Lubricants, Petroleum coke, Refinery feed stocks, Other oil (aviation gasoline), Anthracite, Coking coal, Sub-bit coal, Lignite, Oil shale, Peat, BKB and patent fuel, Coke oven/Gas coke, Natural gas (dry), Solid biomass, liquid biomass and Gas biomass. 
study, a detailed breakdown of the data sources used by DEAT, for the different sectors, highlighting the main players in each case.

\subsection{The Department of Energy's inventories [11]}

The South African Department of Energy (DoE) published emissions inventories for 2007 and 2008. These inventories report emissions in $\mathrm{CO}_{2}$ equivalent for five main sectors (namely industrial, commercial, agricultural, transport and residential) that are disaggregated into 22 industries. To calculate the sectoral emissions, the 1996 IPCC emission factors were used ${ }^{4}$. The DoE assumes that nuclear and renewable energy carriers do not emit at all (transformation sector). Also, owing to data availability, it assumes that sectors such as 'non-ferrous metals', 'transport equipment', 'textile and leather', 'international civil aviation', 'domestic air transport' and 'pipeline transport' do not emit. In reality there is data available on electricity consumption but electricity is not viewed as a fuel source in this respect since emissions during the final consumption of electricity are considered to be zero.

\subsection{The International Energy Agency's inventories [9]}

The International Energy Agency (IEA) published emission inventories for 1971, $1975,1980,1985,1990$ and 1995. The IEA is therefore the only source of a comprehensive time series emissions inventory for South Africa. The IEA states (IEA, 2011) that although the 2006 IPCC guidelines are generally approved, the majority of the countries are still using the 1996 IPCC guidelines for their inventories and hence, for now, the IEA follows the same approach. These inventories report total emissions by various fuel types. Also, the IEA disaggregates the total emissions into the following sectors: 'energy industries', 'manufacturing industries and construction', 'transport' with 'road transport' separately, 'other sectors' with 'residential sector' separately. The total emissions in the IEA inventory come only from the combustion of coal, oil and gas and only represent $\mathrm{CO}_{2}$ emissions, and not $\mathrm{CO}_{2}$-eqv.

2.7 The inventory based on Blignaut et al. [5]

Blignaut et al. [5] compiled an emissions inventory for 1998 using the national energy balance as published by the Department of Minerals and Energy and the IPCC 1996 guidelines. $\mathrm{CO}_{2}$ and $\mathrm{CO}_{2}$ equivalent for $\mathrm{CH}_{4}$ and $\mathrm{N}_{2} \mathrm{O}$ emissions were calculated per sector and per fuel group. The inventory covers emissions in 40 economic sectors for 8 fuel types ${ }^{5}$. This sectoral disaggregation reconcile to the 1998 social accounting matrix of South Africa.

\subsection{Summary}

Based on the information presented above, the respective inventories can be summarised as follows:

- The Scholes and Van der Merwe [3] and Howells and Solomon [4] inventories were both constructed for only one year, 1988 and 1994 respectively, and has become relatively dated. The Scholes and Van der Merwe (1996) inventory provides a useful reference point in terms of total emissions; however, the disaggregation cannot be reconciled with the national energy balance sectors. The inventory constructed by Howells and Solomon (2000) provides a useful

\footnotetext{
${ }^{4}$ Personal communication with Department of Energy.

${ }^{5}$ Fuel types used: Coal, Crude oil, Petroleum, Gas, Nuclear, Hydro, Renewables and Electricity.
} 
reference for $\mathrm{CO}_{2}$ emissions for 1994. However, $\mathrm{CH}_{4}$ and $\mathrm{N}_{2} \mathrm{O}$ emissions are only available as percentage contribution per sector to total emissions for the specific $\mathrm{GHG}$. The $\mathrm{CO}_{2}$ equivalent is therefore not available.

- The DEAT inventory, while it includes a high level of disaggregation with an allinclusive approach, is relatively dated providing an inventory only until 2000.

- The DoE inventory has recent data and on a high level of disaggregation; however, it has several drawbacks. It assumes that nuclear and renewable energy carriers do not emit at all. Also, it assumes that sectors such as 'nonferrous metals', 'transport equipment', 'textile and leather', 'international civil aviation', 'domestic air transport' and 'pipeline transport' do not emit.

- The IEA database, while providing useful information for the comparison analysis with other countries, neither provides disaggregated emissions per sector nor includes other (non- $\mathrm{CO}_{2}$ ) greenhouse gas emissions. The total emissions in the IEA inventory come only from the combustion of coal, oil and gas and only represent $\mathrm{CO}_{2}$-emissions, and not $\mathrm{CO}_{2}$-eqv.

- The Blignaut et al. [5] inventory provides a high level of disaggregation per sector and per fuel group. However, it covers only 1998 and has become relatively dated.

In essence, the ideal inventory is one that achieves the same level of disaggregation as DEAT inventory and a certain level of continuity as that of the DoE inventory. Given these inadequacies there is a need for compiling a recent, allinclusive and comprehensive emissions inventory to represent as accurately as possible the country's status quo greenhouse gas emissions. In an attempt to do so, the energy balance information for energy consumption in 2007 and 2008 from the Department of Energy is used to calculate an inventory that could be used in economic analysis and modelling. To test its robustness, it is compared regarding both the total emissions with all the other inventories listed above and the sectoral levels with the DoE database. To develop this inventory, the methodology proposed in Blignaut et al. [5] is used, which will produce two sets of results. One set (UP1) will use the emission factors from Blignaut et al. [5] (based on 1996 IPCC Emissions Guidelines [12]) and the other set (UP2) will, for the most part, use the emission factors from the new 2006 IPCC Emissions Guidelines [13] while some country-specific factors will be used from Blignaut et al. [5].)

\section{INVENTORY CONSTRUCTING METHOD}

\subsection{Introduction}

Based on the discussion above it is evident that there is a need to construct an emission inventory that is consistent with the economic/industrial sector of South Africa, and that reflects appropriate emission levels. To do this, a 2007 and a 2008 emission inventory will be constructed based on Blignaut et al. (2005) using various emission factors. These will then be compared with the published inventories and, thereafter, a few robustness tests will be conducted.

As per Blignaut et al. [5], the consumption from the DoE energy balance will be used to calculate the $\mathrm{CO}_{2-}, \mathrm{CH}_{4}-$ and $\mathrm{N}_{2} \mathrm{O}$-emissions per sector for 2007 and 2008 using various emissions factors. The years 2007 and 2008 were selected as the DoE published an emissions inventory from 2007 to 2009, but at the time of writing a final version of the 2009 inventory has not yet been released. These are also years following the publication of the 2006 IPCC Emissions Guidelines [13]. This methodology allows the mapping of emissions by sector in a way that is inherently 
consistent across sectors. In addition, the energy consumption by sector will be mapped in standardised and in native units.

In the inventory, emissions of each GHG will be expressed in carbon dioxide equivalents, based on the global warming potential that measures the relative radiation forcing of different GHGs over a specific period. These global warming potentials over a century time horizon are 1,21 and 310 for carbon dioxide, methane and nitrous oxide respectively, as recommended by the Intergovernmental Panel on Climate Change [12]. Furthermore, to avoid double-counting Blignaut et al. [5] is followed who argue that "[e]lectricity is not viewed as a fuel source in this respect since emissions during the final consumption of electricity are considered to be zero. Electricity is viewed as a sector that consumes fuel". Electricity is used as a final product but there are no emissions to the environment when consumed. Electricity emits GHG only during the transformation (generation) process.

\subsection{Carbon dioxide emissions: Coal-based $\mathrm{CO}_{2}$-emissions}

The emission of $\mathrm{CO}_{2}$ depends on the quantity and type of fuel used and follows the laws of material balance and thermodynamics. The amount of $\mathrm{CO}_{2}$ emitted was calculated using a sectoral approach, with some modifications (see IEA (2001) for details). The sectoral approach implies the calculation of emissions using fuel consumption in different energy sub-sectors. Emissions of $\mathrm{CO}_{2}$ from coal combustion were calculated by multiplying the quantity of coal consumed in each sector by an effective emission factor for coal in that sector.

\subsection{Carbon dioxide emissions: Non-coal-based $\mathrm{CO}_{2}$-emissions}

Carbon dioxide emissions from non-coal fossil fuel sources were calculated in a similar way to that of coal, namely by multiplying the fuel consumption in each sector by the respective emission factor. The basis for the estimate is the fuel used in different energy sectors, grouped into the fossil fuel categories according to its aggregate condition namely crude oil, petrol, diesel, other petroleum, gas and renewables. The carbon content factors used for calculations were distinguished by fuel source and were obtained from IPCC guidelines on emission factors.

\subsection{Carbon dioxide emissions: General}

In general, as shown in equation 1, the carbon dioxide emission factors were calculated by multiplying the carbon emission factors (adjusted for oxidation) of a particular fuel by $44 / 12 \mathrm{kgCO}_{2}$ per kilogram of carbon, and multiplying that product by the energy amount of that fuel consumed.

$$
\mathrm{CO}_{2}=\sum\left[\text { ACTIVITY } \times E F \times \frac{44}{12}\right]
$$

Where:

$\mathrm{CO}_{2} \quad$ carbon dioxide emissions from fossil fuel combustion (in $\mathrm{Gg}$ )

ACTIVITY fuel consumption converted to TJ

EF emissions factor, equal to carbon coefficient multiplied by oxidation-

44/12 molecular weight ratio of $\mathrm{CO}_{2}$ to carbon. 
Because not all carbon is oxidised, a relevant oxidation factor will be applied.

\subsection{Non-carbon dioxide emissions}

The sources of methane and nitrous oxide emissions include combustion sources only, and was computed using the following approach:

$$
G A S=A C T I V I T Y \times E F
$$

Where:

ACTIVITY fuel consumption converted to TJ

EF emission factor, expressed as $\mathrm{kg} / \mathrm{TJ}$

In order to be consistent with the methodology used for carbon, IPCC default guidelines are used to account for the emission of methane. For nitrous oxide from the transport sector, default IPCC emission factor values are used. It will be assumed that in 2006 all cars were equipped with three-way catalysts.

\section{RESULTS}

The results of estimating the GHG emissions for 2007 and 2008 in comparison with the other existing studies are shown in Table 1 and Figure 1.

The most complete time series is the IEA inventory, first published in 1971. When comparing the IEA inventory with the other inventories, it should be kept in mind that the IEA inventory only includes $\mathrm{CO}_{2}$ emissions. It is, therefore, in line with expectations that the emissions recorded in the IEA inventory are below total emissions reported in other inventories and could be considered as an absolute minimum emission per annum. However, the increase in $\mathrm{CO}_{2}$ emissions are in line with increases in total emissions as estimated by the other inventories.

From Table 2 and Figure 1 it can be deduced that for each inventory where more than one year is estimated (IEA, DEAT, IEA, DoE, UP1 and UP2), GHG emissions increased between every consecutive available time period. The exception is the 2009 IEA inventory, the only inventory with emission results for 2009, which shows a $4.9 \%$ decline in emissions between 2008 and 2009. This is in line with expectations, given negative economic growth over the same time period.

The DoE inventory with total emission of $95240 \mathrm{Gg}$ in 2007 and $132985 \mathrm{Gg}$ in 2008 warrants a more detailed discussion, if the IEA inventory is seen as the absolute minimum emission per annum (since it only includes $\mathrm{CO}_{2}$ emissions). This difference will be discussed in more detail in the next section. 
Table 2 Total GHG emissions of South Africa in Gg by inventory

\begin{tabular}{|c|c|c|c|c|c|c|c|c|c|}
\hline & $\begin{array}{c}\text { Scholes } \\
\text { and Van } \\
\text { der Merwe } \\
{[3]^{1}}\end{array}$ & $\begin{array}{c}\text { Howells } \\
\text { and } \\
\text { Solomon } \\
{[4]^{2}}\end{array}$ & DEAT[6 ${ }^{3}$ & $\begin{array}{l}\text { DOE } \\
{[7,8]^{4}}\end{array}$ & IEA [9] $^{5}$ & $\begin{array}{c}\text { Blignaut } \\
\text { [5] }\end{array}$ & UP1 ${ }^{6}$ & UP2 $^{7}$ & $\begin{array}{l}\text { Median } \\
\text { UP }\end{array}$ \\
\hline 1971 & & & & & 173800 & & & & \\
\hline 1975 & & & & & 209200 & & & & \\
\hline 1980 & & & & & 214500 & & & & \\
\hline 1985 & & & & & 229100 & & & & \\
\hline 1988 & $\begin{array}{l}366054 \\
(378916)\end{array}$ & & & & & & & & \\
\hline 1990 & & & 347346 & & 254700 & & & & \\
\hline 1994 & & 326406 & 379842 & & & & & & \\
\hline 1995 & & & & & 276900 & & & & \\
\hline 1998 & & & & & & 352932 & & & \\
\hline 2000 & & & $\begin{array}{l}433243 \\
(435462)\end{array}$ & & 298200 & & & & \\
\hline 2005 & & & & & 330300 & & & & \\
\hline 2007 & & & & 95240 & 356500 & & 427767 & 503495 & 465631 \\
\hline 2008 & & & & $132985^{8}$ & 388400 & & 468529 & 550794 & 509662 \\
\hline 2009 & & & & & 369400 & & & & \\
\hline
\end{tabular}

Notes:

1 The number without parenthesis reflect the total for $\mathrm{CO}_{2}, \mathrm{CH}_{4}$ and $\mathrm{N}_{2} \mathrm{O}$ only, while the number in parenthesis also include $\mathrm{CO}, \mathrm{NO}_{x}$ and $\mathrm{NMVOC}$ emissions.

${ }^{2}$ The number only reflects $\mathrm{CO}_{2}$ emissions. $\mathrm{CO}_{2}, \mathrm{CH}_{4}, \mathrm{~N}_{2} \mathrm{O}, \mathrm{NO}, \mathrm{CO}, \mathrm{NMVOC}$ and $\mathrm{SO}_{2}$ have been reported by activity as percentage of the specific $\mathrm{GHG}$ emissions.

3 The number without parenthesis reflect the total for $\mathrm{CO}_{2}, \mathrm{CH}_{4}$ and $\mathrm{N}_{2} \mathrm{O}$ only, while the number in parenthesis also include HFC's, PFCs and $\mathrm{SF}_{6}$ emissions.

${ }^{4}$ DoE assumes no emissions in nuclear, renewable and a selection of other sectors (see discussion in section 2.5).

${ }^{5}$ Only $\mathrm{CO}_{2}$ emissions are included.

${ }^{6}$ The emissions are calculated using the same emission factors from Blignaut et al. (2005), but applied to the energy balances of $2007 \& 2008$.

${ }^{7}$ The emissions are calculated using the IPCC [13] revised emission factors as well as some country specific factors from Blignaut et al. [5], and applied to the energy balances of 2007 \& 2008.

${ }^{8}$ DOE published various preliminary versions of the 2009 emissions inventory, but has not yet published a final emission inventory for 2009.

The main predicament of using the Blignaut et al. [5] and the DEAT inventories is the fact that they present the emissions for 1998 and 2000 respectively. Therefore, to secure some continuity between these two, it is necessary to make sure that the change between the periods 1998, 2000 and 2007 is as expected: showing a realistic positive trend in line with the country's economic growth. The growth from 1998 to 2000, using the databases of Blignaut et al. [5] and DEAT, implies an annual increase of about 4\%. Taking the DEAT database as fixed for 2000 and comparing it with UP1, a negative growth rate is reflected; while compared with UP2 it shows a marginal annual increase of $1.65 \%$. These are low numbers when compared to DEAT, but highly plausible when compared to Blignaut et al. (2005). The negative UP1 growth rate and the marginal UP2 growth rate is because the DEAT emissions inventory includes non-energy use agriculture emissions, totalling $21289 \mathrm{Gg}$ of $\mathrm{CO}_{2}$-eq (4.9\% of total emissions) and therefore the emissions estimate is higher than what the energy balances, which excludes non-energy use agriculture emissions, can support. 


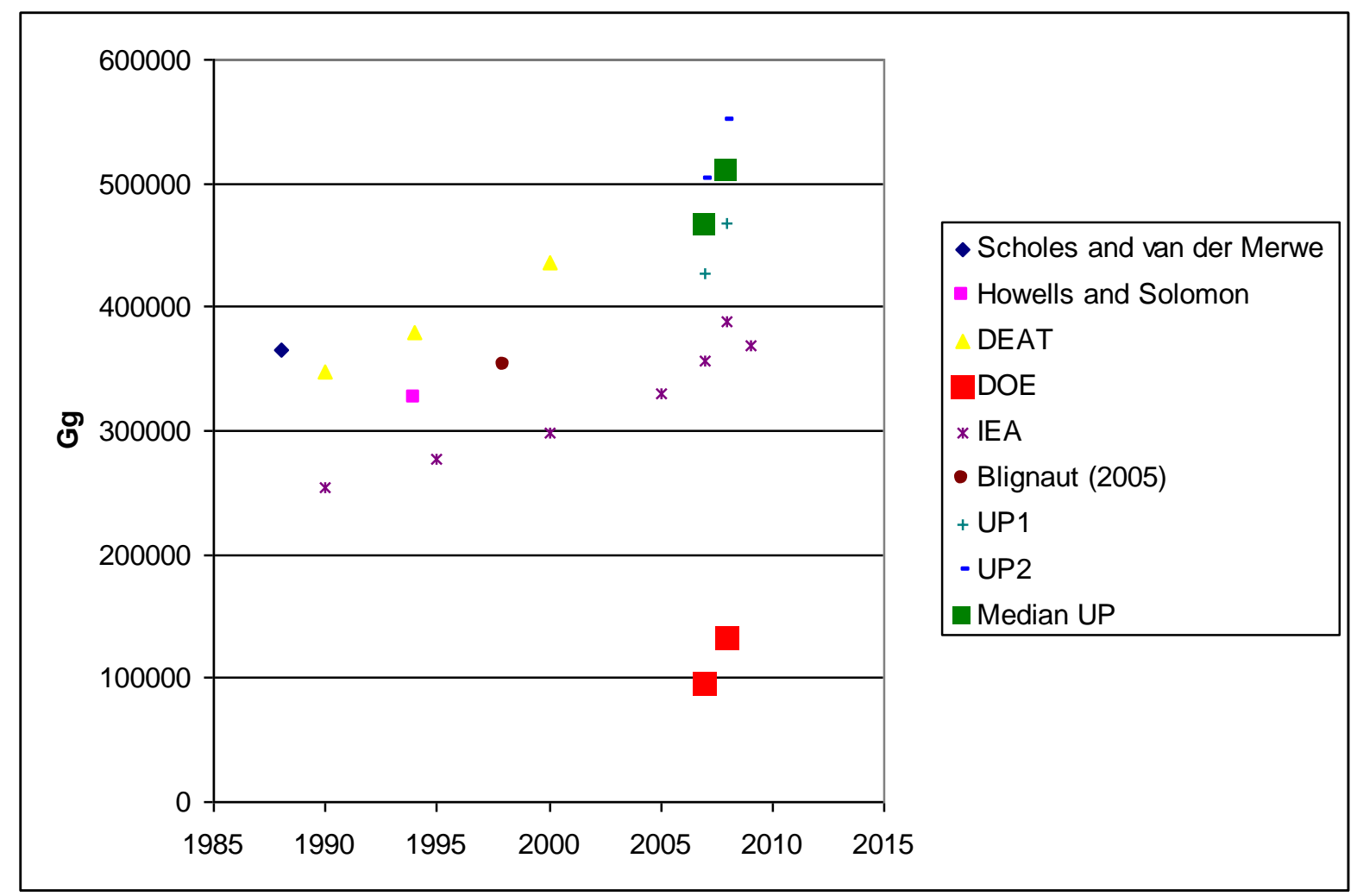

Figure 1 Total GHG emissions for South Africa

Sources: Scholes and Van der Merwe [3]; Howells and Solomon [4]; Blignaut et al. [5]; DoE [7]; DEAT [6]; IEA [9]; and authors' calculations

Figure 1 presents the different inventories as a scatter diagram. The UP inventories are of the same order of magnitude of that of Scholes and Van der Merwe [3], Howells and Solomon [4], Blignaut et al. [5], and DEAT [6], providing for increases in emissions over time as per the economic growth rate. UP inventories are above IEA (2011) inventory levels, but this is expected since UP inventories include $\mathrm{CO}_{2}$, $\mathrm{CH}_{4}$ and $\mathrm{N}_{2} \mathrm{O}$ emissions and the IEA (2011) only report $\mathrm{CO}_{2}$ emissions.

The two UP inventories have the same level and type of disaggregation as the DoE database in order to investigate sectoral differences (and indicate possible sectors whose emissions the DoE might underestimate). The UP inventory uses the Blignaut et al. (2005) emission factors, based on the 1996 IPCC Emissions Guidelines (UP1), and the unofficial inventory uses the 2006 IPCC Emissions Guidelines emission factors (UP2) - these are shown in the first two columns of Table 3. It should be noted here that some emission factors were adopted from Blignaut et al. (2005) in the second version as they were more country-specific (see Table 3). The DoE emissions inventory by sector is shown in column three.

As mentioned before, the underlying reason for these significant differences is the DoE inventory's assumption of no emissions from the use of natural gas, electricity, renewables, nuclear and crude oil. Also, according to the DoE inventory, sectors such as 'non-ferrous metals', 'transport equipment', 'textile and leather', 'international civil aviation', 'domestic air transport' and 'pipeline transport' did not emit at all in 2007. 
Table 3 South African sectoral GHG emissions in Gg per sector for 2008

\begin{tabular}{|c|c|c|c|}
\hline & UP1 ${ }^{1}$ & UP2 $^{2}$ & DoE $^{3}$ \\
\hline TOTAL EMISSIONS & 468529.71 & 550794.80 & 132985.46 \\
\hline Transformation sector total & 295743.70 & 352026.17 & 89980.78 \\
\hline Public Electricity Plant & 215923.46 & 239368.49 & 62830.91 \\
\hline Autoproducer Electricity Plant & 3084.54 & 3829.70 & 1005.24 \\
\hline Public CHP Plant & 0.00 & 0.00 & 0.00 \\
\hline Autoproducer CHP Plant & 23627.05 & 26050.63 & 0.00 \\
\hline Public Heat Plant & 0.00 & 0.00 & 0.00 \\
\hline Autoproducer Heat Plant & 0.00 & 0.00 & 0.00 \\
\hline Heat pumps & 0.00 & 0.00 & 0.00 \\
\hline Electric boilers & 0.00 & 0.00 & 0.00 \\
\hline Gas Works & 0.00 & 0.00 & 229.85 \\
\hline Oil Refineries & 11980.99 & 11975.56 & 657.02 \\
\hline Coal Transformation & 0.00 & 0.00 & 0.00 \\
\hline Liquefaction & 41127.66 & 70801.80 & 25257.75 \\
\hline Non-specified (Transformation) & 0.00 & 0.00 & 0.00 \\
\hline Own Use & 0.00 & 0.00 & 0.00 \\
\hline Distribution Losses & $\begin{array}{l}0.00 \\
0.00\end{array}$ & $\begin{array}{l}0.00 \\
0.00\end{array}$ & $\begin{array}{l}0.00 \\
0.00\end{array}$ \\
\hline Total Final Consumption & 172786.01 & 198768.62 & 43004.68 \\
\hline Industry Sector & 46513.84 & 58597.04 & 15591.92 \\
\hline Iron and Steel & 16271.12 & 19550.01 & 6183.32 \\
\hline Chemical and Petrochemical & 6007.88 & 8104.47 & 2026.62 \\
\hline Memo: Feedst.Use In Petchem.Ind. & 0.00 & 0.00 & 0.00 \\
\hline Non-Ferrous Metals & 0.00 & 0.00 & 0.00 \\
\hline Non-Metallic Minerals & 3482.43 & 4232.22 & 1110.37 \\
\hline Transport Equipment & 0.00 & 0.00 & 0.00 \\
\hline Machinery & 129.45 & 130.10 & 30.27 \\
\hline Mining and Quarrying & 6917.67 & 8054.97 & 2142.91 \\
\hline Food and Tobacco & 77.64 & 78.04 & 18.16 \\
\hline Paper Pulp and Print & 173.48 & 174.36 & 40.57 \\
\hline Wood and Wood Products & 0.00 & 0.00 & 0.00 \\
\hline Construction & 1726.23 & 1825.51 & 521.32 \\
\hline Textile and Leather & 0.00 & 0.00 & 0.00 \\
\hline Non-specified (Industry) & 11727.93 & 16447.37 & 3518.37 \\
\hline Transport Sector & 63602.19 & 67783.03 & 16674.33 \\
\hline International Civil Aviation & 2608.99 & 2759.04 & 0.00 \\
\hline Domestic Air Transport & 3229.57 & 3415.30 & 0.00 \\
\hline Road & 50137.40 & 53020.87 & 14322.26 \\
\hline Rail & 151.64 & 683.35 & 181.00 \\
\hline Pipeline Transport & 0.00 & 0.00 & 0.00 \\
\hline Internal Navigation & 7474.59 & 7904.46 & 2171.08 \\
\hline Non-specified (Transport) & 0.00 & 0.00 & 0.00 \\
\hline Other sectors & 62669.98 & 72388.56 & 10738.43 \\
\hline Agriculture & 3408.25 & 3623.92 & 988.39 \\
\hline Commerce and Public Services & 11328.09 & 13421.04 & 3571.99 \\
\hline
\end{tabular}


Note: The percentage differences between the three different approaches are shown in Annexure 2.

${ }^{1}$ The emissions are calculated using the exact emission factors from Blignaut et al. (2005).

2 The emissions are calculated using the IPCC (2006) revised emission factors as well as some country specific factors from Blignaut et al. (2005).

${ }^{3}$ The figures of this column are derived from the Energy Balances (DoE, 2008) unmodified.

The transformation sector accounts for more than $63 \%$ of total GHG emissions in South Africa during 2008. Based on the UP1 and UP2 inventories, the industry, transport and other sectors each contribute between $9 \%$ and $14 \%$ to total GHG emissions.

\section{COMPARATIVE ANALYSIS: UP inventories and DoE inventory, 2008}

The previous section focused on the total GHG emissions as reported in the various inventories as well as calculated with UP1 and UP2. This section compares the DoE inventory with the UP1 and UP2 inventories, not only on total emission levels, but also on sectoral level.

In addition to the previous points, a comparison with the IEA database figures for South Africa's $\mathrm{CO}_{2}$-emissions in 2007 also provides a justification on the underestimation of DoE and the closer representation of the UP1 and UP2. According to IEA [9], South Africa emitted in total $356500 \mathrm{Gg}$ of $\mathrm{CO}_{2}$-emissions (not including $\mathrm{CH}_{4}$ and $\mathrm{NO}_{2}$ ) in 2007; while according to UP1, the $\mathrm{CO}_{2}$-emissions are estimated to be $342822 \mathrm{Gg}$ and UP2 estimated $385561 \mathrm{Gg}$. This shows that UP1 is $4 \%$ lower than the IEA [9] estimation while UP2 is $12.5 \%$ higher, a fact attributed to the use of the newest IPCC (2006) emission factors. In contrast, the DoE database estimates that the sum of GHG emissions was $95240 \mathrm{Gg}(27 \%$ of the IEA [9] estimation for $\mathrm{CO}_{2}$-emissions only).

Another way to confirm that DoE underestimates the total emissions of the economy is as follows. Blignaut et al. [5] estimated that the electricity generation sector contributed $65.9 \%$ of total emissions in 1998. Taking into account that Eskom emitted 223.6mil tons (223 600Gg) in 2007/08 [14] and assuming the proportion remained the same, the total emissions should be no less than approximately 339 000Gg.

As shown in Figure 2(a), these significant differences between the DoE inventory on the one hand and the Blignaut et al. (2005) and the 2006 IPCC Emissions Guidelines [13] on the other hand extend to all the sectors. The differences between DoE and the two other inventories, on sector level, are between $198 \%$ and 574\% while the differences between the Blignaut et al. [5] and the 2006 IPCC Emissions Guidelines [13] are between 6\% and 21\%. 
Figure 2 Total emissions (Gg) by sector

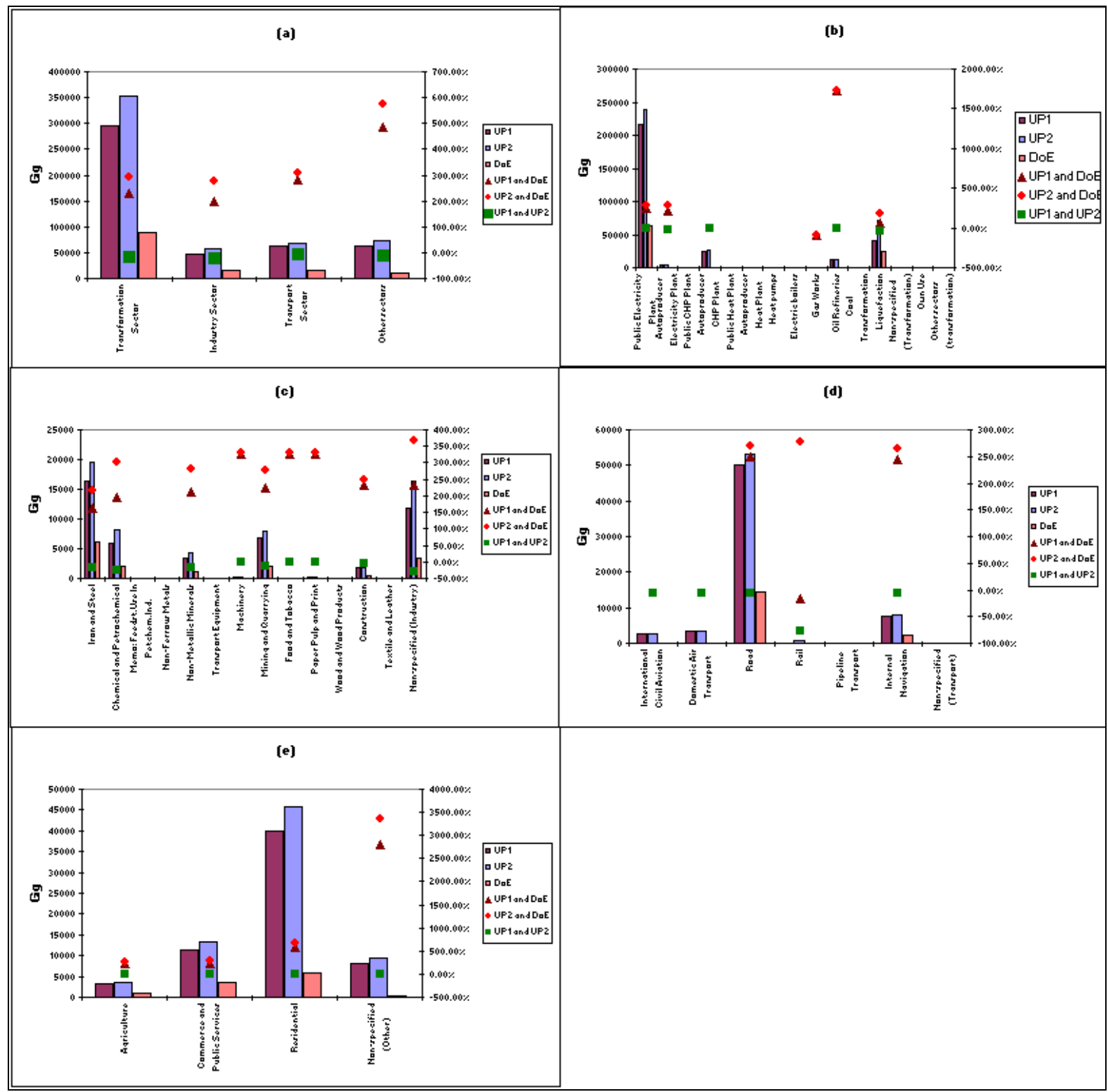

Source: Own analysis

Notes: Figure $2 \mathrm{a}$ represents $; 2 d$ ; $2 \mathrm{e}$ $2 \mathrm{c}$

In the graphs, , UP1 and UP2 are this paper's databases; DoE are the ones from Department of Energy. The triangle depicts the difference between UP1 and DoE; the circle the difference between UP2 and DoE; and the square the difference between UP1 and UP2.

According to the DoE inventory, emissions for the transformation sector are approximately $90000 \mathrm{Gg}$. However, the energy consumed according to the DoE Energy Balances is reported in negative values. To understand the negative sign, it should be noted that a portion of the total primary energy supply is transformed into other forms of energy, e.g. coal and crude oil are transformed to electricity and petroleum products respectively. Energy used during this transformation process is, therefore, not part of the final consumption component. Another way to think about 
it is that the transformation sector shows inputs (resources) into a process as a negative value and outputs (commodities) as a positive. The difference between the two presents a net inflow (outflow), if negative (positive), and shows the total amount of fuel going into (coming out of) a process. To calculate emissions, the interest lies with the fuel that is combusted in the transformation process, therefore the negative numbers.

Emissions in the transformation sector, as shown in Figure 2(b), are driven by the public electricity sub-sector. It is evident that the DoE inventory's assumption of no emissions from the use of electricity drives the differences in emissions between the inventories. The differences between the two versions of the UP inventory move in a narrow band of between $0 \%$ and $19 \%$, except for the liquefaction (42\%) sub-sector. However, these differences, although relatively high in percentage terms on sub-sector level, translate into comparatively small absolute numbers. As percentage of total aggregate emissions, the liquefaction difference is approximately $6 \%$.

Also based on the two UP inventory versions, emissions in the industry sector, when disaggregated to sub-sector level (as shown in Figure 2(c)), are dominated by the 'iron and steel', 'non-ferrous metals' and 'mining' sub-sectors. But, according to the DoE inventory, the 'non-ferrous metals' sub-sector had no emissions and the 'iron and steel' as well as 'mining' sub-sectors had relatively low emissions. This explains the roughly $300 \%$ to $360 \%$ differences between the DoE inventory and the Blignaut et al. [5] and 2006 IPCC Emissions Guidelines [13]. Differences between Blignaut et al. [5] and the 2006 IPCC Emissions Guidelines [13] for all three dominating sectors are between $14 \%$ and $26 \%$.

Disaggregating the transport sector (Figure 2(d)) and other sectors (Figure 2(e)) reveal similar patterns. The databases that use the Blignaut et al. [5] and the 2006 IPCC Emissions Guidelines [13] inventories show relatively similar emission levels per sub-sector, with differences ranging between $5 \%$ and $16 \%$, with the exception of rail. The 'rail' sub-sector shows a difference of $78 \%$. However, this amounts to approximately $0.1 \%$ of total emissions. The DoE inventory underestimates emissions relative to the first two approaches in all the sub-sectors by between $217 \%$ and $3351 \%$.

Based on the consistent similarity between the Blignaut et al. [5] and the 2006 IPCC Emissions Guidelines inventories, as well as the methodological rigor of both approaches, compared to the ambiguous treatment of several sectors in the DoE inventory, the suggested inventory to use is either the inventory constructed using the same emission factors as Blignaut et al. [5] or the one using the 2006 IPCC Emissions Guidelines. The latter, however, provides more robust results for the following reasons:

- The emission factors from the 2006 IPCC Emissions Guidelines [13] are much more recent.

- This database combines certain emissions factors from the Blignaut et al. [5] study in order to capture some country-specific situations.

- The DEAT emissions for 2000 are calculated with the 2006 IPCC Emissions Guidelines [13] emission factors. Hence, continuity can be achieved and it will be of assistance for a comparative exercise.

- The comparison between UP1 and DEAT emissions shows that there was a small decrease of emissions between 2000 and 2007 which cannot be 
confirmed by a priori expectations. On the contrary, UP2 presents an increase of $4 \%$ annually from Blignaut et al. (2005), which seems plausible.

- Both estimations from UP1 and UP2 are in the same order of magnitude with the database by the IEA [9]. In reality, UP1 presents $4 \%$ less than the amount of $\mathrm{CO}_{2}$-emissions as indicated in the IEA (2011) and UP2 presenting an amount $8 \%$ higher due to the use of more recent emission factors [13].

\section{CONCLUSION}

This paper developed a GHG emissions inventory for 2007 and 2008 in terms of industrial sectors, using the energy balances of South Africa as reference.

The DoE, DEAT, as well as the IEA published emissions data for South Africa. However, there seems to be inconsistencies between the different emission datasets.

- The IEA database, while providing useful information for the comparison analysis with other countries, neither provides disaggregated emissions per sector nor includes other (non- $\mathrm{CO}_{2}$ ) greenhouse gas emissions.

- The DoE has recent data and on a desired level of disaggregation; however, due to data gaps it probably underestimates emissions.

- The DEAT inventory, while it includes a high level of disaggregation with an allinclusive approach, is relatively dated providing an inventory only until 2000.

The focus of the comparative analysis was on the 1998 inventory (based on Blignaut et al. [5]), and 2007 and 2008, which are the first years for which the DoE published an official emissions inventory in conjunction with their regular Energy Balances [8]. This provided both a starting point for the compilation of the emission database and a point of reference with respect to the level of emissions.

In essence, the desired database is one that achieves the same level of disaggregation as the DEAT inventory and a certain level of continuity as in the DoE inventory. Given these inadequacies, there is a need for compiling a recent, allinclusive and comprehensive emissions inventory to represent as accurately as possible the country's status quo greenhouse gas emissions.

In an attempt to do so, the energy balance information for energy consumption in 2007 and 2008 from the DoE was used to calculate an inventory suitable for economic analysis and modelling. To test its robustness, the total emissions was compared to all the other reports listed above and the sectoral levels were compared to the DoE database.

To develop this inventory, the methodology proposed in Blignaut et al. [5] was used. This produced two sets of results. One set (UP1) used the emission factors from Blignaut et al. [5] (based on 1996 IPCC Emissions Guidelines) and the other set (UP2) predominantly used the emission factors from the new 2006 IPCC Emissions Guidelines with some factors from Blignaut et al. [5] to ensure a few country-specific characteristics.

From the comparative analysis it was evident that the DoE emissions database underestimates greenhouse gas emissions. Based on the consistent similarity between the Blignaut et al. [5] and the 2006 IPCC Emissions Guidelines [13] inventories, as well as the methodological rigor of both approaches, compared to the ambiguous treatment of several sectors in the DoE inventory, the suggested 
inventory to use is either the inventory constructed using the same emission factors as Blignaut et al. [5] or the one using the 2006 IPCC Emissions Guidelines.

\section{REFERENCES}

[1] UNSDI 2011

[2] Quantec. 2012. World Development Indicators. Available at: http://quanis1.easydata.co.za/TableViewer/tableView.aspx?Reportld=21225 (accessed on 31/07/2012).

[3] Scholes, R.G. \& Van der Merwe, M.R. 1996. Greenhouse Gas Emissions from South Africa. South African Journal of Science, 92:220-222.

[4] Howells, M.I. \& Solomon, M. 2000. South African Greenhouse Gas Energy Emissions Inventory for the Year 1994. Journal of Energy, 11(4):272-278.

[5] Blignaut, J.N., Chitiga-Mabugu, M.R. \& Mabugu, R.M. 2005. Calculating a Greenhouse Gas Emissions Database Using Energy Balances: The Case of South Africa 1998. Journal of Energy in Southern Africa, 16(3):105-116.

[6] Department of Environment Affairs and Tourism (DEAT). 2009. Greenhouse Gas Inventory South Africa: 1990-2000. Pretoria: Department of Environment Affairs and Tourism.

[7] Department of Energy (DoE). 2007. Energy Balances. Pretoria: Department of Energy.

[8] Department of Energy (DoE). 2008. Energy Balances. Pretoria: Department of Energy.

[9] International Energy Agency (IEA). 2011. $\mathrm{CO}_{2}$ emissions from fuel combustion - Highlights, 2011 Edition. Paris: IEA.

[10] Boyd, A.B., Rennkamp, B., Winkler, H., Larmour, R., Letete, T., Rahlao, S. and Trikam, A. 2012. South African Approaches to Measuring, Reporting and Verifying: A Scoping Report. The Measurement and Performance Tracing Project. World Resources Institute.

[11] Department of Energy (DoE). Various issues. Energy Balances. Pretoria: Department of Energy.

[12] Intergovernmental Panel on Climate Change (IPCC). 1996. IPCC Guidelines for National Greenhouse Gas Inventories. Hayama: Institute for Global Environmental Strategies.

[13] Intergovernmental Panel on Climate Change (IPCC). 2006. IPCC Guidelines for National Greenhouse Gas Inventories. Hayama: Institute for Global Environmental Strategies.

[14] Blignaut, J.N. 2011. The external cost of coal-fired power generation: The case of Kusile. Annex 2: Climate change: the opportunity cost of Medupi and Kusile power stations. Pretoria: Greenpeace South Africa. 
ANNEXURE 1: PERCENTAGE DIFFERENCES IN 2008 CO2-EQUIV. EMISSION LEVELS BY SECTOR AMONG VARIOUS METHODS OF CALCULATION

\begin{tabular}{|c|c|c|c|}
\hline & \multicolumn{3}{|l|}{$\%$ Difference } \\
\hline - & $\begin{array}{l}\text { Between } \mathrm{UP}^{1}{ }^{1} \text { and } \\
\text { DoE }\end{array}$ & $\begin{array}{l}\text { Between } \mathrm{UP2}^{2} \text { and } \\
\text { DoE }\end{array}$ & Between UP1 ${ }^{1}$ and UP2 ${ }^{2}$ \\
\hline TOTAL EMISSIONS & $252 \%$ & $314 \%$ & $-15 \%$ \\
\hline Transformation Sector & $229 \%$ & $291 \%$ & $-16 \%$ \\
\hline Public Electricity Plant & $244 \%$ & $281 \%$ & $-10 \%$ \\
\hline Autoproducer Electricity Plant & $207 \%$ & $281 \%$ & $-19 \%$ \\
\hline Public CHP Plant & & & \\
\hline Autoproducer CHP Plant & & & $-9 \%$ \\
\hline Public Heat Plant & & & \\
\hline Autoproducer Heat Plant & & & \\
\hline Heat pumps & & & \\
\hline Electric boilers & & & \\
\hline Gas Works & & & \\
\hline Oil Refineries & $1724 \%$ & $1723 \%$ & $0 \%$ \\
\hline Coal Transformation & & & \\
\hline Liquefaction & $63 \%$ & $180 \%$ & $-42 \%$ \\
\hline Non-specified (Transformation) & & & \\
\hline Own Use & & & \\
\hline Distribution Losses & & & \\
\hline Total consumption & & & \\
\hline Total Final Consumption & $302 \%$ & $362 \%$ & $-13 \%$ \\
\hline Industry Sector & $198 \%$ & $276 \%$ & $-21 \%$ \\
\hline Iron and Steel & $163 \%$ & $216 \%$ & $-17 \%$ \\
\hline Chemical and Petrochemical & $196 \%$ & $300 \%$ & $-26 \%$ \\
\hline Memo: Feedst.Use In Petchem.Ind. & & & \\
\hline Non-Ferrous Metals & & & \\
\hline Non-Metallic Minerals & $214 \%$ & $281 \%$ & $-18 \%$ \\
\hline Transport Equipment & & & \\
\hline Machinery & $328 \%$ & $330 \%$ & $-1 \%$ \\
\hline Mining and Quarrying & $223 \%$ & $276 \%$ & $-14 \%$ \\
\hline Food and Tobacco & $328 \%$ & $330 \%$ & $-1 \%$ \\
\hline Paper Pulp and Print & $328 \%$ & $330 \%$ & $-1 \%$ \\
\hline Wood and Wood Products & & & \\
\hline Construction & $231 \%$ & $250 \%$ & $-5 \%$ \\
\hline Textile and Leather & & & \\
\hline Non-specified (Industry) & $233 \%$ & $367 \%$ & $-29 \%$ \\
\hline Transport Sector & $281 \%$ & $307 \%$ & $-6 \%$ \\
\hline International Civil Aviation & & & $-5 \%$ \\
\hline Domestic Air Transport & & & $-5 \%$ \\
\hline Road & $250 \%$ & $270 \%$ & $-5 \%$ \\
\hline Rail & $-16 \%$ & $278 \%$ & $-78 \%$ \\
\hline Pipeline Transport & & & \\
\hline
\end{tabular}


Internal Navigation

Non-specified (Transport)

Other sectors

Agriculture

Commerce and Public Services

Residential

Non-specified (Other)

Note: ${ }^{1}$ The emissions are

${ }^{2}$ The emissions are calculated using the IPCC (2006) revised emission factors as well as some country-specific factors from Blignaut et al.[5].
$-5 \%$

$\begin{array}{lll}484 \% & 574 \% & -13 \% \\ 245 \% & 267 \% & -6 \% \\ 217 \% & 276 \% & -16 \% \\ 576 \% & 676 \% & -13 \%\end{array}$

$2806 \% \quad 3351 \% \quad-16 \%$ 